\title{
Desbravando novos territórios: incorporação da Terapia Ocupacional na estratégia da saúde da família no município de São Paulo e a sua atuação na atenção à saúde da pessoa com deficiência - no período de 2000-2006*
}

\author{
Breaking new grounds: incorporation of \\ Occupational Therapy at the family health strategy \\ in São Paulo and its performance on the health \\ care of people with disabilities
}

\author{
Mariana Hernandes Antunes ${ }^{1}$, Eucenir Fredini Rocha ${ }^{2}$
}

\begin{abstract}
ANTUNES, M. H.; ROCHA, E. F. Desbravando novos territórios: incorporação da Terapia Ocupacional na estratégia da Saúde da Família no município de São Paulo e a sua atuação na atenção à saúde da pessoa com deficiência - no período de 2000-2006. Rev. Ter. Ocup. Univ. São Paulo, v. 22, n. 3, p. 270-278, set./dez. 2011.
\end{abstract}

\begin{abstract}
RESUMO: O presente artigo aponta os resultados da pesquisa sobre a incorporação das ações de Terapia Ocupacional (TO) na estratégia de Saúde da Família (SF) no município de São Paulo, em nove Unidades Básicas de Saúde - Fundação Zerbini/Região Sudeste-Sapopemba/Vila Prudente, no período de 2000 a 2006. Discute as características, as contribuições, os limites e os modos de operar da Terapia Ocupacional na assistência das pessoas com deficiência na atenção primária à saúde, a partir da análise qualitativa de entrevistas semi-estruturadas realizadas com três terapeutas ocupacionais, doze profissionais com outras formações e quatro usuários dos serviços. A análise dos depoimentos identificou sete estruturas temáticas que permitiram compreender o trabalho da TO: demanda e organização das ações; características e modalidades de atendimento; material e infraestrutura; visão dos outros profissionais e usuários sobre a TO; pontos satisfatórios e insatisfatórios; contribuições para a efetivação da integralidade e sugestões para a melhoria do trabalho. Concluiu que a SF é um espaço apropriado para atenção às necessidades de saúde das pessoas com deficiência e que a TO tem nele possibilidades de ações propositivas e efetivas na garantia do acesso, da integralidade da assistência, na prevenção e promoção da saúde e melhora da qualidade de vida. No entanto, há necessidade de expandir a compreensão sobre as potencialidades da profissão, além de objetivar nas atividades de planejamento dos serviços suas participações e prever na organização da infra-estrutura dos equipamentos condições adequadas à sua ação.
\end{abstract}

DESCRITORES: Terapia Ocupacional; Atenção Primária à Saúde; Atenção Básica, Saúde da família; Reabilitação; Pessoas com deficiência.

\footnotetext{
* Projeto financiado pela FAPESP - Processo n06/55138-3. Esteve integrado ao projeto de pesquisa financiado pelo CNPq sob o título "Avaliação da Implantação das Ações de Reabilitação no Programa de Saúde da Família (PSF) da Fundação Zerbini e Secretaria Municipal de Saúde de São Paulo - Região Sudeste - Sapopemba/Vila Prudente - período 2000/2006 - Edital MCT-CNPq / MS-DAS/SAS - No 49/2005; Processo n402234/05-7, sob a responsabilidade de Rocha E.F e Kretzer, M. R.

1. Instituto Nacional do Seguro Social (INSS) - Gerência Executiva de Jundiaí.

2. Prof $^{\mathrm{a}} \mathrm{Dr}^{\mathrm{a}}$ do Departamento de Fisioterapia, Fonoaudiologia e Terapia Ocupacional da Faculdade de Medicina da Universidade de São Paulo.

Endereço para correspondência: Rua Cipotânea, 51 - Cidade Universitária. CEP: 05360-160 - São Paulo, SP.
} 


\section{APRESENTAÇÃO}

$\mathrm{E}$ ste artigo visa relatar os resultados da pesquisa de iniciação científica que investigou a incorporação da Terapia Ocupacional (TO) na estratégia de Saúde da Família (SF) no município de São Paulo no período de 2000-2006, enfocando sua atuação na atenção à saúde das pessoas com deficiência, no Projeto Programa Saúde da Família-Qualidade em Saúde (PSF) QUALIS), uma parceria entre o Ministério da Saúde, a Secretaria Estadual de Saúde e a Casa de Saúde Santa Marcelina (QUALIS I) e Fundação Zerbini (QUALIS II) ${ }^{(1)}$ (SÃO PAULO, 2000).

O QUALIS foi implantado em Unidades Básicas de Saúde (UBS) em três regiões administrativas da cidade: leste, sudeste e norte, territórios com alta densidade demográfica e baixa oportunidade de acesso a recursos públicos e sociais.

No QUALIS I e II foram organizadas duas equipes de reabilitação compostas por fisioterapeutas, fonoaudiólogos e terapeutas ocupacionais e a dinâmica do trabalho foi constituída para que esses profissionais atuassem em conjunto com as equipes de SF. Para tanto, os profissionais de reabilitação foram organizados em duplas ou trios em um trabalho orientado por princípios interdisciplinares e cada um deles era referência para nove ou dez equipes de SF (Quadro 1). As pessoas com deficiência e incapacidades foram identificadas pelos profissionais das equipes de $\mathrm{SF}$ e de reabilitação, após a discussão de suas necessidades foram encaminhados para procedimentos específicos na área.

Quadro 1 - Equipes de Saúde da Família abrangidas por região X Número de UBS abrangidas pelo QUALIS X Número de profissionais das equipes de reabilitação de referencia às equipes de SF X Número de profissionais de reabilitação por categoria X Número de duplas/ trio de profissionais de reabilitação organizadas em cada região

\begin{tabular}{|c|c|c|c|c|c|c|c|c|}
\hline & \multirow{2}{*}{$\begin{array}{c}\text { Equipes } \\
\text { de saúde } \\
\text { da família } \\
\text { abrangidas }\end{array}$} & \multirow[t]{2}{*}{$\begin{array}{l}\text { Número de UBS } \\
\text { abrangidas pelo } \\
\text { QUALIS }\end{array}$} & \multirow{2}{*}{$\begin{array}{l}\text { Número de profissionais } \\
\text { das equipes de } \\
\text { reabilitação de referência } \\
\text { às equipes de SF }\end{array}$} & \multicolumn{3}{|c|}{$\begin{array}{l}\text { Número de } \\
\text { profissionais de } \\
\text { reabilitação por } \\
\text { categoria } \\
\end{array}$} & \multicolumn{2}{|c|}{$\begin{array}{l}\text { Número de duplas/trio de } \\
\text { profissionais de reabilitação } \\
\text { organizadas em cada região. }\end{array}$} \\
\hline & & & & FI & FO & TO & Duplas* & Trio** \\
\hline $\begin{array}{l}\text { Região Leste - Casa de } \\
\text { Saúde Santa Marcelina } \\
\text { (QUALIS I) }\end{array}$ & 89 & 15 & 18 & 08 & 05 & 05 & 09 & - \\
\hline $\begin{array}{l}\text { Região Sudeste - } \\
\text { Fundação Zerbini } \\
\text { (QUALIS II) }\end{array}$ & 33 & 09 & 09 & 03 & 03 & 03 & 03 & 01 \\
\hline TOTAL & 122 & 24 & 27 & 11 & 08 & 08 & 12 & 1 \\
\hline
\end{tabular}

*Duplas: terapeuta ocupacional/fonoaudiólogo; terapeuta ocupacional/fisioterapeuta; fisioterapeuta/ fonoaudiólogo

**Trio: fisioterapeuta/ fonoaudiólogo/ terapeuta ocupacional

Fonte: ROCHA et al., 2001

As atividades educativas, preventivas, de planejamento, de avaliação e intersetoriais foram parte do repertório das ações dos profissionais de reabilitação para contribuir com a inclusão e defesa de direitos das pessoas com deficiência, viabilizando a participação destas pessoas nas atividades da comunidade, e afirmando a integralidade no atendimento.

Ao estabelecer uma relação permanente com os sujeitos, considerando os aspectos objetivos e subjetivos inerentes a cada pessoa, família, comunidade e cotidiano, assegurou-se o caráter polissêmico do princípio da integralidade, recusou-se o reducionismo, que restringi o sujeito à patologia, desconsiderando suas necessidades como pessoa e o seu entorno (MATTOS, 2004). Assim, a integralidade foi considerada o eixo condutor do projeto, como direito e como serviço.

Almeja-se aqui compreender como as ações de terapia ocupacional se inseriram nas propostas da estratégia da SF no QUALIS II- Fundação Zerbini/Região SudesteSapopemba/Vila Prudente, suas contribuições, limites e

(1) Casa de Saúde Santa Marcelina: Organização Social, com a missão de desenvolver ações e serviços de saúde no âmbito da região leste do município de São Paulo. Em 1996 implantou Programa Saúde da Família (PSF). Fundação Zerbini: instituição de direito privado e de utilidade pública, filantrópica, beneficente e sem fins lucrativos, foi responsável pela implantação e gestão do PSF, no período de 2000/2008, nas regiões sudeste e norte do município. 
modos de operar nesse nível assistencial.

\section{PROCEDIMENTOS METODOLÓGICOS}

A pesquisa realizada é de natureza qualitativa e teve caráter exploratório, pois se propôs a apresentar uma visão panorâmica de um tema ainda pouco estudado. Para tanto, o fenômeno - a inserção das ações de TO na estratégia da SF - foi interpretado a partir dos depoimentos e análises que os sujeitos envolvidos, os profissionais de saúde e os usuários, deram às práticas desenvolvidas (GONSALVES, 2003).

Foram entrevistados doze profissionais das equipes de SF, sendo: dois médicos, um enfermeiro, um auxiliar de enfermagem, dois agentes comunitários de saúde, um dentista, um auxiliar de odontologia, dois fisioterapeutas, dois fonoaudiólogos, os três terapeutas ocupacionais da equipe de reabilitação e mais quatro usuários atendidos pela $\mathrm{TO}$, totalizando dezenove entrevistas.

Os profissionais e usuários preencheram o termo de consentimento, aprovado pelo Comitê de Ética da Secretaria Municipal de Saúde de São Paulo(2) e após a aprovação da pesquisa realizou-se contato com a Fundação Zerbini para informar sobre a pesquisa, que por sua vez notificou os profissionais das equipes de SF.

Os entrevistados foram selecionados, em sua maioria, por sorteio, apenas os terapeutas ocupacionais foram entrevistados em sua totalidade. Os usuários foram sorteados a partir das listas preparadas pelos terapeutas ocupacionais, e a condição para participar era que a pessoa tivesse ao menos um ano de atendimento de TO.

Os membros da equipe de reabilitação foram contatados através de telefone para formalizar o convite e efetuar o agendamento da entrevista. Os profissionais das equipes de SF e da saúde bucal tiveram o convite e o agendamento realizado por intermédio do diretor da UBS enquanto os usuários tiveram o convite e o agendamento realizado por através dos Agentes Comunitários de Saúde (ACS) responsáveis pela área de residência da família.

As entrevistas dos profissionais foram realizadas no ambiente de trabalho e dos usuários em suas residências, na sua maioria. Apenas um dos terapeutas ocupacionais teve sua entrevista realizada nas dependências do Centro de Docência e Pesquisa do Departamento de Fisioterapia, Fonoaudiologia e Terapia Ocupacional da Faculdade de Medicina da Universidade de São Paulo e dos usuários, apenas uma entrevista ocorreu na UBS. Utilizou-se um local reservado, onde o entrevistado pudesse falar sem intimidações sobre suas opiniões.

Para a coleta de dados a estratégia foi entrevistas individuais, semi-estruturadas, que foram gravadas e transcritas para análise posterior.

Para os usuários assistidos pela TO foi questionado: há quanto tempo era atendido pela TO; porque foi encaminhado ou procurou a TO; o que fazia no atendimento; o que mais gostava desse trabalho; o que menos gostava; o que gostaria de realizar, mas ainda não conseguia (em relação ao seu desempenho pessoal); o que não conseguia fazer antes e alcançou com a TO; se a TO ajudava em alguma atividade do seu dia-a-dia e se poderia dar um depoimento sobre o que entendia, ou quais foram os benefícios da TO no seu tratamento.

Em relação aos profissionais das equipes de SF, de odontologia e de reabilitação indagou-se: há quanto tempo trabalhava na UBS; o que conhecia sobre as atividades do terapeuta ocupacional; dentro da organização das equipes, qual era o papel e a importância da TO; como qualificava o trabalho da TO com as pessoas com deficiência; o que era considerado satisfatório e insatisfatório do trabalho; o que sugeririam para o aprimoramento do trabalho da TO na SF.

E para os terapeutas ocupacionais se questionou: há quanto tempo trabalhava na SF; se fez algum curso de pós-graduação e qual; quais eram as ações/atividades desenvolvidas junto com as pessoas com deficiência; quais as demais atividades da TO realizadas dentro da SF; como era organizado o trabalho de equipe e qual é o papel do terapeuta ocupacional; para quantas equipes a TO era referência; para quantos usuários e quantos desses eram atendidos freqüentemente; o que considerava satisfatório e insatisfatório no trabalho; que materiais utilizavam; qual a freqüência dos atendimentos, reuniões de equipes e outras atividades; o que sugeriam de aprimoramento para os TO na SF; o que faltava para desenvolver no seu trabalho; se utilizavam de alguma metodologia específica, qual e por quê; quais eram as contribuições da TO na integralidade da assistência.

O tratamento dos dados apoiou-se na "concepção de comunicação como processo e não como um dado estatístico, e do discurso como palavra em ato" (MINAYO, 1994, p.206). Para o desenvolvimento da análise utilizouse uma abordagem de análise qualitativa conhecida como "Abordagem da Estrutura", organizada em cinco etapas

(2) Parecer no. 0228/06 - Comitê de ética em Pesquisa - Secretaria Municipal da Saúde - Coordenação de Desenvolvimento de programas de Políticas de Saúde -CODEPPS. 
distintas (POPE et al., 2006): 1. Familiarização: escuta das entrevistas e leitura e re-leitura das transcrições; 2 . Identificação de uma estrutura temática: identificação dos núcleos de sentido que compõem as entrevistas; 3 . Indexação: sistematização dos dados de acordo com as estruturas temáticas eleitas como foco da análise, através de anotações na margem da transcrição; 4. Mapeamento e reorganização dos dados das entrevistas de acordo com as estruturas temáticas; 5 . Mapeamento e Interpretação: utilização dos registros para definir conceitos e desenvolver a interpretação de acordo com os objetivos gerais da pesquisa.

\section{RESULTADOS E DISCUSSÃO DOS DADOS}

O tratamento dos dados coletados resultou em sete estruturas temáticas: 1. demanda e organização das ações; 2. modalidades de atendimento; 3. material e infra-estrutura; 4. visão dos profissionais e usuários sobre a TO; 5. pontos satisfatórios e insatisfatórios; 6 . contribuições para a efetivação da integralidade e 7. sugestões para a melhoria do trabalho.

\section{Demanda e Organização das Ações}

As ações de TO se constituíram a partir dos encontros com as equipes de $\mathrm{SF}$ e aqueles que ocorriam entre os profissionais da equipe de reabilitação, através de reuniões anuais, mensais e quinzenais.

Nas reuniões anuais, com todos os profissionais da UBS, ocorria o planejamento das estratégias a serem implementadas pelas equipes, já nas reuniões mensais se discutia os novos casos de pessoas com deficiências/ incapacidades detectados, situações e problemáticas do território, ações de prevenção, educação e promoção da saúde e coordenação de casos.

Em reuniões quinzenais ocorriam os encontros dos profissionais de reabilitação, que discutiam os casos e o trabalho com as equipes de SF, organizavam contatos intersetoriais e exercitavam as possibilidades de intervenções com base na interdisciplinaridade, através de trocas de conhecimentos:

A gente faz muitas discussões, por exemplo, vou falar do meu trio, várias vezes pacientes de mão, por exemplo, a TO atende uma vez, eu atendo outra vez, assim a gente vê o paciente duas vezes por semana, já aconteceu isso, eu começar atender, comigo já foi tudo que eu tinha que conseguir fazer com esse paciente, já cessou as minhas possibilidades, ai eu encaminho pra a TO e ela faz, tenta ganhar mais função naquela mão mesmo, então a gente senta e discute bastante(...) (Fisioterapeuta 1).

As atividades comuns a todos os profissionais de reabilitação consistiam em: identificação dos usuários com deficiências; o matriciamento das equipes de SF, saúde bucal e mental; atividades de prevenção, de educação, intervenções junto aos usuários; participação nas reuniões das equipes de SF, da saúde bucal e mental; participação no planejamento institucional; organização de fluxos internos e externos às UBS, no SUS e em atividades intersetoriais.

A equipe de reabilitação em conjunto com as equipes de SF, detectou em estudo censitário nas nove UBS, 4476 pessoas com uma ou mais tipos de deficiências ou incapacidades, classificadas de acordo com as categorias da Classificação Internacional de Deficiências, Incapacidades e Desvantagens (OMS, 1989). Havia na época uma média de 1492 pessoas com deficiência para cada um dos terapeutas ocupacionais (ROCHA et al., 2004) que associado a percepção das equipes de SF das intervenções da TO na resposta à diminuição dos agravos e problemas de saúde de pessoas com incapacidades severas gerou demanda reprimida.

Observou-se também que as equipes que contavam com TO em sua referência reconheciam com maior agilidade a necessidade de suas ações:

(...) nos postos que tem terapeuta ocupacional, as pessoas que trabalham, eles sabem o que éo trabalho do terapeuta ocupacional, pra quê que ele veio, o quê que ele faz, isso é importante, porque não é uma profissão tão conhecida, então a gente vê que é uma constante capacitação dos profissionais, de como encaminhar um paciente pro $T O(. .$.$) (Fonoaudiólogo 1).$

\section{Modalidades de atendimento da Terapia Ocupacional}

O terapeuta ocupacional desenvolvia ações de estimulação em crianças de alto risco ou com alguma deficiência, trabalho de movimentação corporal passiva e ativa, alongamentos, adaptações nos instrumentos dos usuários para realização de Atividades de Vida Diária e da Vida Prática, tecnologia assistiva, inclusão escolar e social, facilitação da independência e da autonomia, mobilização de recursos e constituição de redes de apoio e organização do cotidiano para melhoria na qualidade de vida; enquanto as discussões sobre a deficiência e direitos com usuários, equipes e coordenadores, ações intersetoriais, acompanhamento e suporte das famílias procuravam objetivar aspectos inerentes à integralidade na assistência.

A ação na estratégia da SF permitiu um acompanhamento mais próximo dos usuários e da família, 
uma maior responsabilização pela saúde e qualidade de vida do usuário o quê não seria possível se esse trabalho fosse realizado em um centro de reabilitação:

(...) pelo fato do tratamento ser muito longo, tem maior vínculo com a família, acho que pela SF você consegue mudar vários hábitos do cotidiano daquela família que talvez numa clínica você não conseguisse, não estaria ali convivendo, fazendo as visitas (...) (fisioterapeuta 1).

O trabalho da TO viabilizou o acompanhamento dos usuários por períodos longos, mesmo quando eles deixavam de ter uma assistência direta, pois continuavam acompanhados pelas equipes de SF, através de três estratégias de intervenção: individuais, coletivas e acompanhamento à distância.

Os atendimentos individuais podiam ocorrer tanto na UBS, como no domicílio e foi nessa modalidade assistencial que esteve concentrado o maior número de intervenções terapêuticas ocupacionais e que demandavam um maior tempo para a sua execução.

(...)A TO é que mais faz visita, a gente já tem uma agenda mais focada nisso, então o número de visitas nossas é muito grande, praticamente grande parte da minha semana eu passo em visita domiciliar, atendimento ou em visitas mais esporádicas ou visita de avaliação, realmente é um momento muito grande da nossa carga horária (TO3).

Os casos considerados graves e acamados ficaram preferencialmente sob a responsabilidade dos terapeutas ocupacionais, o que tornava o domicilio o único local para realizar a intervenção.

As estratégias coletivas foram consideradas pelos profissionais como aquelas que mais potencializam propostas de independência, autonomia e participação social, no entanto, os usuários da TO tinham muitas dificuldades de participar de grupos, pois essa atividade exigia deslocamento, o que nem sempre erai viável.

A TO se inseriu em várias atividades grupais já existentes nas UBS, como grupos de acolhimento e de promoção e prevenção à saúde para desenvolver ações terapêuticas ocupacionais preventivas e educativas, como o monitoramento de crianças com alteração no desenvolvimento, orientação de pacientes com dor crônica, entre outras atividades, que variavam de acordo com as necessidades de cada território:

(...) se tem um bebê que está faltando no grupo de puericultura e é ali que eu vou ter que acompanhar o desenvolvimento dele, e tem alguma questão nessa família que eu tenho que acompanhar também, então eu posso, de repente, se eu sei que ele vai passar no grupo de puericultura no dia tal, então a minha entrada é no grupo de puericultura, eu pego essa criança lá(...) (TO3).

O acompanhamento à distância era o atendimento que não tinha assiduidade, decorrente de vários fatores: quando as opções de intervenção estavam esgotadas, quando o usuário ou família se recusava a participar do trabalho desenvolvido, entre outras. Esses casos passaram a ser monitorados nas reuniões das equipes de SF, quando se decidia se era necessária uma nova avaliação da conduta a ser tomada.

\section{Material e Infra-Estrutura}

Os materiais utilizados pela TO eram obtidos através de verbas de cada uma das UBS, no entanto, aqueles específicos da área tiveram maior dificuldade de serem obtidos, como por exemplo materiais para órteses, pois não havia na Secretaria Municipal de Saúde de São Paulo verba específica para esses itens.

Dessa maneira, vários materiais substitutivos foram utilizados, em geral, mais simples e de fácil acesso para a população, como objetos provenientes da casa do usuário, sucatas e artefatos e elementos de texturas diferentes, brinquedos, jogos e material de papelaria (argila, massinha, giz, lápis de cor, cola, tinta, etc.).

A opção por materiais e objetos de fácil acesso da população, muitas vezes facilitou e garantiu uma maior adesão ao tratamento, pois não exigiam gasto financeiro:

(...) eu uso as coisas do cotidiano, até porque eu sei que tem coisas que se eu pedir, pela carência, as famílias não vão comprar, então, também não adianta muito eu levar o melhor material do mundo que eu tenho no posto... e mostrar pra pessoa que ela não vai ter igual (...) (terapeuta ocupacional 2).

No entanto, os entrevistados ressaltaram a necessidade de aquisição de alguns equipamentos específicos como, tablado, bola Bobath, cadeira de rodas, bengalas de diferentes tipos e andador, importantes nos atendimentos.

Quanto ao espaço físico nas UBS foram relatadas inúmeras dificuldades, porque a maioria dos equipamentos só contava com espaços para pequenos consultórios, que eram utilizados em forma de rodízio por todos os profissionais de saúde:

(...) elas ficam meio, meio, por conta do espaço físico 
mesmo, a gente não tem, sempre vai depender de um consultório que estiver vazio (...) a gente não tem espaço físico suficiente, então o cara não pode nem, de repente, ter um consultório dele com o material dele montado, pra você ter uma noção, está ali o material da TO e da psico, é aquele, do pessoal da fono, elas colocam tudo lá, quer dizer, elas não têm um consultório, esse consultório aqui é meu, então quando sobra um lugarzinho, pode ser no arquivo, na sala de coleta de papa(...) (médico 2).

Essa realidade, muitas vezes, inibiu as possibilidades de ações grupais ou dirigidas à população com deficiência e incapacidade, pois além do espaço exíguo, como falta de salas para essas atividades, as UBS também tinham muitas barreiras arquitetônicas, presença de escadas e corredores estreitos que dificultava a circulação de usuários com deficiência motora e ausência de banheiros adaptados.

\section{Visão dos Profissionais e Usuários sobre a Terapia Ocupacional}

Os entrevistados afirmaram que o terapeuta ocupacional, por sua formação acadêmica, contribuiu para ampliar a visão das equipes acerca dos processos de saúde-doença, independência, autonomia, direitos, inclusão e contribuiu para uma visão menos reducionista, fato que repercutiu nas intervenções:

(...) tem TO que ajuda muito nas discussões, de pensar mesmo (...) poder olhar de várias maneiras um determinado assunto (...) eles ajudam muito numa discussão para ampliar o olhar, de você poder entender melhor (...) isso enriquece muito. (fonoaudiólogo 1).

Todavia, muitos dos entrevistados tiveram dificuldades para definir as especificidades da TO e recorreram à comparações com outras profissões:

(...) eu acho que é assim, a TO é um, é aquele profissional que fica entre ofono e a fisio, que ele consegue fazer essa interface, porque a fono trabalha muito com aprendizagem e tem haver com vários aspectos de psicomotricidade (...) (fisioterapeuta 1).

(...) realmente ela ajuda, não é que nem uma fisioterapeuta, mais chega perto, orientam as pessoas, elas tentam fazer com que elas voltem a ter uma vida mais ou menos normal (...) (agente comunitário de saúde 2).

(...) achava legal o trabalho deles, como se fosse o fisioterapeuta, com um psicólogo, é tudo junto (...) (auxiliar de enfermagem).

Outra estratégia utilizada pelos entrevistados para definir a TO é caracterizá-la pela enumeração das atividades executadas ou pelas patologias e agravos de saúde dos usuários assistidos pela TO:

(...) ele trabalha mais com deficientes mentais e às vezes físicos também, (...) faz parte da nossa brinquedoteca, então é um trabalho todo pra criança também (...) (agente comunitário de saúde 1).

(...) ele tenta trazer ele de volta para atividade, familiar, interação com a própria família, com os profissionais de saúde, fazer com que ele retome as atividades normais, a inclusão, que normalmente em qualquer trauma desses que a pessoa tem, o que a pessoa já vem do nascimento, ou comprometimento por alguma coisa, ele tem essa característica de se fluir (...) (enfermagem).

(...) tem paciente neurológico, tem pacientes ortopédicos, com fraturas, de dedos, mão, punho (...) tem aqueles casos também que não tem uma patologia, mas sei lá, senilidade, uma idade avançada o que você consegue fazer algumas adaptações no mobiliário, nos utensílios domésticos que dá pra fazer o atendimento (...) (fisioterapeuta 1).

Deve se destacar que muitos entrevistados consideram o terapeuta ocupacional como sendo um profissional de "ampla", atuação capaz de atuar em diferentes aspectos, patologias e áreas de interface com diversas profissões:

(...) é que TO na verdade é uma coisa muito ampla, dá pra trabalhar vários aspectos, tanto na equipe de saúde mental, acaba atuando junto (...) Acho que, na verdade, dá pra contribuir em tudo (...) (fisioterapeuta 1).

(...) a gente vê que é um profissional que consegue ir por vários caminhos (...) (agente comunitário de saúde 1).

(...) a TO é uma área bem ampla de atuação, é uma área muito inteira, conversa muito bem com a fisio, muito bem com a mental, muito bem com a fono, pela proximidade, fica próximo (...) (fonoaudiólogo 2).

Eu sei que ele, na realidade, pega o paciente com problema físico, normalmente, e adéqua o meio em que ele vive, pra que ele tenha mais facilidade pra fazer suas atividades diárias, é isso que eu conheço do trabalho deles (...) (dentista).

\section{Pontos Satisfatórios e Insatisfatórios da Terapia Ocupacional na SF}

É importante destacar que durante a realização das entrevistas no questionamento sobre os pontos satisfatórios e insatisfatórios do trabalho da TO na SF, houve a necessidade de explicar aos entrevistados o que se pretendia compreender com a questão, pois a maioria teve dificuldade para descrever os pontos insatisfatórios do trabalho da 
TO, por pensarem se tratar de questões pessoais com os profissionais da categoria.

Para os terapeutas ocupacionais entrevistados, o principal ponto de satisfação foi a oportunidade de trabalhar em um modelo de saúde, denominado por eles de "enriquecido", uma vez que na SF são desenvolvidas ações em equipe, existe uma variedade de situações e complexidade dos casos, atividades de prevenção, deteç̧ão precoce de situações de risco, trabalho com famílias e flexibilidade nas formas para se conduzir os casos.

Para os outros profissionais, a presença da TO nas equipes de SF proporcionou acompanhamentos em longo prazo, formação mais ampla das equipes, suporte em questões que iam além das necessidades físicas do usuário, confecção de adaptações com a finalidade de facilitar as atividades cotidianas.

Já os usuários destacaram melhora na auto-estima, a diminuição da dependência em relação aos cuidadores e o aumento da autonomia, introdução de adaptações e tecnologia assistiva que facilitam as atividades do cotidiano, aceitação da deficiência, melhora nos aspectos físicos, psíquicos, sensoriais e cognitivos.

Quase a metade dos entrevistados (47,6\%) apontaram como insuficiente o número de profissionais em relação a demanda de trabalho:

(...) tem uma demanda muito grande e trabalhamos em três unidades, é uma coisa muito macro, a gente acaba, não só pra TO, mas pra todos os profissionais a insatisfação acaba acontecendo porque a gente não tem tempo, de fazer algo melhor, de ser mais próximo, imagine que o trabalho da TO exija um acompanhamento muito mais próximo da família, ... nós somos em poucos profissionais (...) (FO2).

Eu sei que, por exemplo, no Guairacá eu dedico 3 dias da semana, são 6 equipes e que o tempo não é suficiente e isso que eu divido os atendimentos, como que é isso: tem paciente que eu sei que seria mais beneficiado se eu visse duas vezes, três vezes por semana ou toda semana, mas a demanda é tão grande, tão grande que eu acabo fazendo um trabalho de orientação mesmo, os casos mais graves que precisa, a gente tem que dá uma atenção maior, pelo menos na fase mais aguda. (terapeuta ocupacional 2).

A falta da infra-estrutura e materiais básicos também foi destaque na insatisfação com o trabalho:

(...) não é que é da SF, é enquanto política pública nacional, não tem recurso, não tem dinheiro pra material básico, às vezes não papel, não tem caneta, pra fazer um grupo, por exemplo. Falta espaço fisicico pra atender, em duas unidades eu não tenho sala, cada dia é um lugar diferente, isso é complicado, a gente improvisa... não tem transporte ou a pessoa vive numa situação de miséria extrema (...) (agente comunitário de saúde 2).

Para os terapeutas ocupacionais são obstáculos que comprometem a qualidade do trabalho, a falta de tempo para realizar um trabalho mais próximo às comunidades $\mathrm{e}$ as lideranças locais, dificuldades no trabalho intersetorial, principalmente em relação à inclusão escolar.

Nenhum dos usuários relatou pontos negativos, somente um afirmou que deveria haver mais UBS que realizassem o atendimento proporcionado pela TO.

\section{Contribuições das ações da TO para a efetivação da integralidade}

O conceito de integralidade é reconhecido como a contraposição ao reducionismo e permeia todas as ações de saúde do SUS, desde a assistência, à promoção e à prevenção. Na SF, as equipes são capazes de assimilar esses três tipos de ações, tanto por busca ativa dos casos no território de abrangência, como no acompanhamento ambulatorial. A integração desses conceitos em um mesmo serviço extrapola para as equipes de saúde bucal, saúde mental e reabilitação, tornando as ações desses profissionais componentes essenciais para a concretização da integralidade no atendimento à totalidade dos usuários.

A contribuição da TO para a integralidade é atribuída a sua formação acadêmica. Os terapeutas ocupacionais focam suas ações no fazer humano e na observação dos diversos aspectos que compõem a vida dos sujeitos, auxiliando assim na detecção das necessidades específicas e na elaboração de estratégias para alcançar os objetivos de saúde pretendidos.

Porém, esse trabalho de nada tem valia se os demais profissionais não compreenderem a importância da integralidade no atendimento às pessoas com deficiência. Portanto, pode-se dizer que este é

(...) um trabalho com a unidade como um todo, desde a gerência até quem tá nos serviços gerais, na recepção, como vê a pessoa com deficiencia, ter um banheiro adaptado ou não, como ela chega, enfim, então sem falar das outras coisas, transporte, educação, etc (...) (agente comunitário de saúde 2).

Da mesma forma a responsabilização pelos casos das pessoas com deficiência deve ter um comprometimento de todos os membros das equipes, porém cada qual atuando dentro de suas especificidades. 
(...) tem profissionais que falam: 'esse é um caso da reabilitação'. Então é como que se a partir daquele momento o caso passa a ser só da reabilitação, então a pessoa não vai mais ter gripe, a mulher não vai mais fazer papanicolau, se é criança não vai tomar vacina, ou coisas de rotina que qualquer um tem (...) (terapeuta ocupacional 2).

Pode-se dizer então que muitos profissionais ainda enxergavam os usuários, tendo ou não uma deficiência, como organismos vivos, recortados pelo olhar reducionista da biomedicina, idéias pelas as quais a SF foi elaborado para reverter.

\section{Sugestões para a melhoria do trabalho da Terapia Ocupacional}

Os entrevistados sugeriram algumas modificações que seriam importantes para o aprimoramento do trabalho da TO na SF. Dentre elas:

- Ampliar o contato entre as terapeutas ocupacionais da equipe de reabilitação, com o intuito de aperfeiçoar as formas e estratégias de trabalho;

- Capacitar os profissionais da SF, para que possam compreender melhor as possibilidades e limites da atuação do terapeuta ocupacional;

- Capacitar os TO através de grupos de estudos, com temas específicos e cursos de especialização;

- Prover espaços, equipamentos e materiais adequados às atividades da TO.

- Ampliar os recursos da rede de referência e contra referência em outros níveis assistenciais;

- Contratar um maior número de TO, para reduzir a sobrecarga e aumentar a qualidade de atendimento, diminuindo assim o número de famílias e usuários;

- Maior integração com os outros profissionais de saúde.

\section{CONSIDERAÇÕES FINAIS}

A atenção à saúde das pessoas com deficiência encontra na SF um espaço apropriado para o atendimento de suas necessidades (SÃO PAULO, 2000). A inserção da terapia ocupacional nesse contexto, com estratégias que utilizam tecnologias leves, amplia as possibilidades na assistência.
O acesso se torna mais viável e a integralidade preconizada pelos SUS pode ser garantida também na atenção primária, não apenas nos centros especializados de reabilitação.

A vantagem da utilização das tecnologias leves é que elas consideram as singularidades dos indivíduos e suas necessidades de saúde, independência no cotidiano, aumento das potencialidades de suas funções corporais, objetivando a inserção e a participação na vida social.

O trabalho em equipe, com os profissionais da saúde da família, da reabilitação, saúde bucal e saúde mental, possibilita trocas que aprimoram o conhecimento das diferentes áreas e contribui para a efetivação da integralidade nas ações. A pesquisa demonstrou a importância da Terapia Ocupacional em promover o conhecimento dos outros profissionais sobre suas ações e potencialidades, de maneira que esse trabalho possa reverter na melhora da assistência do usuário, favorecendo a equidade e a integralidade.

Outro aspecto reconhecido pelos profissionais e usuários é a capacidade que a TO possui de atender casos crônicos, direcionando sua ação para a independência e participação social, demonstrando que a atenção primária à saúde é um espaço profícuo para as ações de reabilitação, em detrimento de afirmações que consideram os níveis de média e alta complexidade como o adequado à assistência dessa população.

A necessidade do fortalecimento do trabalho intersetorial também fica reafirmado como uma ação importante da TO nesse nível assistencial, na medida que o conjunto de saberes que a constitui favorece as possibilidades de intervenções grupais e de participação social, além de promover acesso à outros recursos de saúde em outros níveis assistenciais, à escolarização, ao trabalho e acesso à bens culturais.

O setor público da saúde deve ainda se preocupar em se adaptar à chegada desses profissionais, possibilitando acesso a recursos terapêuticos ainda não previstos na atenção primária à saúde, espaços adequados para as intervenções terapêuticas ocupacionais e possibilitando, assim, o acesso pleno das pessoas com deficiências aos serviços de saúde.

Porém ainda existe um longo caminho a se percorrer para que os usuários com deficiência tenham na SF o atendimento que lhes é de direito, que só será atingido quando todos os profissionais envolvidos mudarem a forma de ver e entender suas necessidades de saúde, aprenderem a incluir no seu cotidiano rotinas ou metodologias de investigação sistemática das necessidades mais silenciosas (MATTOS, 2004). 
ANTUNES, M. H.; ROCHA, E. F. Breaking new grounds: incorporation of Occupational Therapy at the Family Health strategy in São Paulo and its performance on the health care of people with disabilities. Rev. Ter. Ocup. Univ. São Paulo, v. 22, n. 3, p. 270-278, set./dez. 2011.

\begin{abstract}
The article points the research results on the incorporation of the actions of Occupational Therapy (OT) in the Family Health (FH) strategy in São Paulo, at nine Basic Health Units - Zerbini Foundation/Southeast Region -Sapopemba/Vila Prudente, between 2000 and 2006. It discusses the characteristics, contributions, limitations and operating modes of Occupational Therapy in the assistance for people with disabilities in primary health care, from the qualitative analysis of semi-structured interviews performed with three occupational therapists, twelve professionals with different degrees and four service users. The analysis of the reports identified seven thematic structures enabled to understand the work of OT: demand and organization of actions; characteristics and modalities of care; material and infrastructure; view of other professionals and users of OT; satisfactory and unsatisfactory points; contributions to the effective of the integrality and suggestions for the improvement of work. It was concluded that the FH is an appropriate space for attention to the health needs of people with disabilities and that the OT has possibilities of purposeful and effective actions in providing access and integrality of assistance, in prevention, health promotion and improvement of life quality. However, there are needs to expand the understanding of the potential of the profession, besides embrancing the planning activities of its services participation and predicting in the organization of the equipment infrastructure the appropriate conditions to its action.
\end{abstract}

KEY WORDS: Occupational therapy; Primary health care; Primary care; Family health; Rehabilitation; Disabled persons.

\title{
REFERÊNCIAS
}

GONSALVES, E. P. Conversas sobre iniciação à pesquisa cientifica. 3a. ed. Campinas: Alínea, 2003.

LUCIANO, A. R. Programa de Saúde da Família/Qualidade Integral em Saúde (PSF/QUALIS). Série Didática n 4. São Paulo: CEDEC., 2002.

MATTOS, R. A. A Integralidade na Prática (ou Sobre a Prática da Integralidade). Cad. Saúde Pública, v. 20, n.5, p. 1411-1416, 2004.

MINAYO, M. C. S. Fase de análise ou tratamento do material. In: $O$ DESAFIO DO CONHECIMENTO: pesquisa qualitativa em saúde. São Paulo: HUCITEC, 1994. p.197-247.

OMS - ORGANIZAÇÃO MUNDIAL DA SAÚDE. Classificação internacional das deficiências, incapacidades e desvantagens (handicaps): um manual de classificação das conseqüências das doenças. Lisboa, 1989.

POPE, C.; ZIEBLAND, S.; MAYS, N. Analisando Dados
Qualitativos. In: POPE, C.; MAYS, N. Pesquisa qualitativa na atenção à saúde. Porto Alegre: Artmed, 2006. p. 87-99.

ROCHA, E. F.; DE PAULA, A. R.; KRETZER, M. R.; DA SILVA, L. B. Avaliação da Implantação do "Programa de Atenção à Saúde da Pessoa Portadora de Deficiência e Reabilitação no PSF/QUALIS nas Regiões Leste e Sudeste do Município de São Paulo - outubro de 2000 a dezembro de 2001". São Paulo, 2001. [Mimeogr.].

ROCHA, E. F.; PAULA, A. P.; KRETZER, M. R. O Estudo de Prevalência de Deficiências e Incapacidades como Instrumento de Planejamento das Atividades de Atenção à Saúde e Reabilitação no Programa de Saúde da Família. Rev. Ter. Ocup. Univ. São Paulo, v.15, n.1, p.1-10, 2004.

ROCHA, E. F. Experiências em Reabilitação: Discutindo a Organização de Serviços e Modelos Assistenciais. In: ROCHA, E. F. (Org.). Reabilitação de pessoas com deficiência: a intervenção em discussão. São Paulo: Roca, 2006. p.61-134.

SÃO PAULO. Projeto Implantação do Programa de Atenção à Saúde da Pessoa Portadora de Deficiência no Programa Saúde da Familia-QUALIS. São Paulo: USP/ Fundação Zerbini/ Secretaria de Estado da Saúde, 2000. 